\title{
RARE CASE OF HUMAN VISCERAL LINGUATULIASIS IN BULGARIA DIAGNOSED ON BIOPSY SPECIMEN
}

\section{Svetlana A. Mateva, Margarita R. Nikolova, Milen P. Karaivanov, Petya E. Marinova ${ }^{1}$}

Dept. of Pathology, Medical University - Pleven, Bulgaria

${ }^{1}$ Alpha Medical-Bratislava Slovakia

\author{
Corresponding Author: \\ Margarita R. Nikolova \\ Department of Pathology \\ Medical University - Pleven \\ 1, St. Kliment Ohridski str. \\ Pleven, 5800 \\ Bulgaria \\ e-mail:mnikol@abv.bg
}

Received: November 11, 2013

Revision received: December 15, 2013

Accepted: December 27, 2013

\begin{abstract}
Summary
We report a rare case of visceral linguatuliasis in a 9-yearold boy. The diagnosis was made incidentally on a biopsy specimen obtained during laparotomy on account of an acute appendicitis. An encysted parasite was found in a mesenteric lymph node and diagnosed as Linguatula serrata larva mainly based on its typical appearance. The vermiform appendix showed only lymphoid hyperplasia and no features of inflammation. The patient made an uneventful recovery after the operation and was discharged. He is being followed up. To our knowledge this is the first officially reported case of human linguatuliasis in Bulgaria.
\end{abstract}

Key words: Linguatula serrata, visceral linguatuliasis

\section{Introduction}

Lingatula serrata (L. serrate) belongs to the phylum Pentastomidae, a group of worm-like parasites with an ill-defined taxonomy and phylogenic status related to arthropods [1-5]. It is a bloodsucking endoparasite in the nasal cavity, larynx and pharynx of domestic and wild carnivorous mammals, which are the final hosts $[1,6,7]$. The habitual intermediate hosts are herbivorous mammals such as sheep, cattle, and rodents [3, 8-10]. Sambon (1922) classified the linguatulids in 13 genera and 43 species [9]. Only six species are known to infect humans, the only ones occurring with noteworthy frequency as human parasites being Armillifer armillatus (a species limited to Africa) and L. serrata $[1-3,5,11,12]$. Although $L$. serrata is distributed worldwide, human infection is infrequent. Humans can be infected in two ways: either as intermediate hosts (visceral linguatuliasis, caused by larval forms) or on rare occasions as accidental final hosts (nasopharyngeal linguatuliasis caused by adult forms) $[2,3,6,5,8,10$, 13]. Nasopharyngeal linguatuliasis occurs after consumption of raw or undercooked viscera (liver, lung and lymph nodes) of sheep, goats or other domestic herbivores infected by encysted nymphs. It is also known as "Halzoun" or "Marrara" syndrome 
(named for the traditional Middle Eastern dish and respectively Sudan's dish, when prepared with raw infected meat) $[1,2,6]$. In these cases, the nymphs emerge from their cysts either in the mouth (in which case they attach directly to the oropharynx) or in the stomach, from where they migrate up the esophagus to the nasopharynx and attach to the mucosa $[1,2,5,10,11]$. Clinically, the nasopharyngeal form is characterized by a hypersensitivity reaction involving the respiratory tract and skin, caused by the presence of an adult parasite in the nasopharynx or by the ingestion of larval proteins. The course of the disease is rapid and benign and about half of such patients recover in less than one day [1]. Visceral linguatuliasis is more frequently described $[2,3,5,6,8,10,13]$ with the highest prevalence reported from the Middle East [12]. Human linguatuliasis is rare in Europe, in United States and China where only a few cases have been reported. In Europe and North America the disease is rarely encountered, and more often seen in immigrants and long-term travellers [12]. Infestation is said to be particularly rarely found in children (Sonobe, 1927) [7]. We found one report on L. serrata infection in goats in the region of North Bulgaria, and none on human linguatuliasis in Bulgaria [8].

We present a case of a human visceral linguatuliasis in a mesenteric lymph node, clinically mimicking acute appendicitis and diagnosed on biopsy specimen. To our knowledge this is the first officially reported case of human linguatuliasis in Bulgaria.

\section{Case presentation}

A 9-year-old boy, who had never traveled abroad, was admitted to the surgical department of a regional hospital complaining of a four-day history of abdominal pain and vomiting. He was initially managed conservatively with antibiotics and analgesics without any obvious effect. Clinical examination revealed palpatory pain in the ileo-coecal region and a slightly enlarged liver. Abdominal X-ray showed a single air-fluid level. Laboratory findings were essentially normal except for a slightly elevated percentage of neutrophil polymorphonuclears $(80 \%)$ and decreased percentage of lymphocytes $(12 \%)$. Acute appendicitis was suspected and a laparotomy was performed. Intraoperative findings were: multiple enlarged mesenteric lymph nodes up to $10 \mathrm{~mm}$ in diameter and a slightly hyperemic and swollen vermicular appendix. Two lymph nodes were sent for histological examination and the appendix was removed. The patient made an uneventful recovery after the operation and was discharged on the seventh post-operative day.

Histological examination of the surgical material revealed intensive lymphoid hyperplasia of the vermiform appendix without any features of inflammation and reactive follicular hyperplasia of lymph nodes. Amongst the parenchyma of one of the two lymph nodes there was a cyst measuring 3-6 $\mathrm{mm}$ with a very scanty surrounding inflammatory reaction. Inside the cystic cavity we found a crescent-

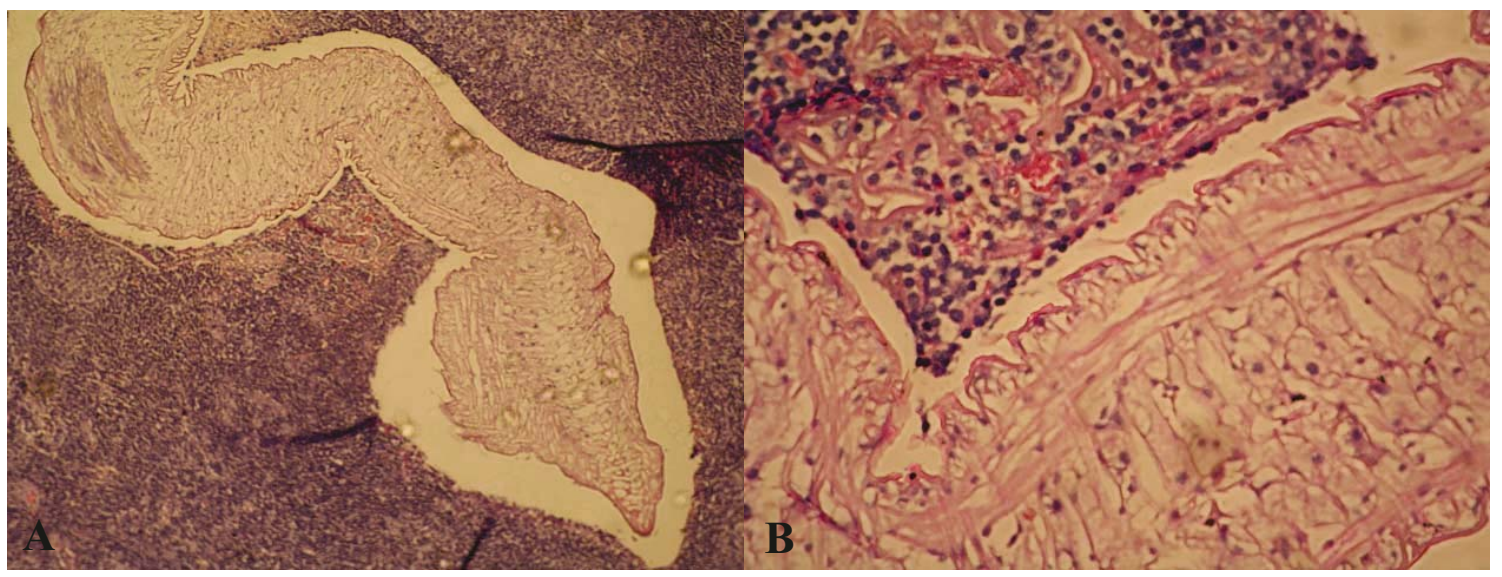

Figure 1. A. Encysted infective, third stage larva of L. serrata with obvious cashew nut shape and well preserved closely placed body-rings each possessing a single set of spines (toothlets). (HEx10). B. Indented chitinous cuticle of $L$. serrata larva and scant inflammatory reaction on the top (HEx40) 
shaped body of a parasite measured 2-4 mm. It was composed of closely packed numerous body rings each possessing a single set of spines (toothlets) that made the chitinous cuticle look clearly serrated (Figure 1A, B).

\section{Discussion}

Visceral linguatuliasis in humans (as aberrant intermediate hosts), is caused by consumption of food or water, contaminated with eggs shed in the environment with nasal discharge or faeces of dogs or other carnivores (final hosts) or perhaps from close contact with an infected cat or dog. The eggs hatch in the intestine and liberated first stage larvae penetrate the intestinal wall, migrate in the abdominal cavity to settle and ultimately encyst in various organs, mainly in the liver and lymph nodes. After several moults within a cyst, a third stage larva (also called nymph or infective larva) emerges from its cyst to migrate again through the peritoneal cavity before re-encysting in various tissues and organs $[2,3,5,6,8,12,13]$. The nymph (Pentastomum denticulatum) is white, $4-5$ by $2-3 \mathrm{~mm}$ in size and its body is segmented by $72-92$ grooves, each possessing a single set of spines. The nymph is embedded in an oval pale cyst with diameter of 2 to $8 \mathrm{~mm}[5,8$, 12]. Although most human infections are asymptomatic, patients may develop abdominal pain, chronic cough or night sweats $[2,3,5,6,8$, 12]. In some cases, when the organ involved is the eye, serious symptoms occur [10] but ocular linguatuliasis is extremely rare with fewer than ten cases described in literature up to now $[3,6]$. Encysted living nymphs do not produce clinical symptoms and the infection is almost always incidentally discovered during surgery, whereas the death of the parasite leads to a prominent host response and lesions may be even confused with malignancy, particularly in lungs $[1,2,3,5,6,8]$. Calcified encysted nymphs give a characteristic C-shaped, circular or horseshoe-shaped opacity on plain abdominal or chest X-rays or may become visible on radiologic examination (Saupe, 1930). They may also be an incidental finding during autopsy [14]. The largest dimension of the lesion is 3 to $6 \mathrm{~mm}$, rarely more $[1,5,12,13]$. Macroscopically, they are nodular or cyst-like, sometimes linked by a short stalk to the serosa or organ surface and are called "Linguatula nodules"[12].

Visceral linguatuliasis often remains a histopathological diagnosis that can be made etiopathologically if a viable nymph is found in a cyst with little or no adjacent cellular infiltration of host tissue $[5,12,13]$. The most important morphological feature of third-stage pentastome larvae (nymphs) encountered in humans is that all they have a smooth cuticle except those of the Linguatula, whose conspicuous spinules are sufficient to differentiate them from all the rest [3]. Diagnosis can also be made subetiopathologically if a dead nymph is found, that is the most common type of lesion in longstanding infections, called necrotic pentastomid granuloma. The parasite is disintegrated and is often calcified but some structures such as oral hooks or the chitinous cuticle, are still present. Finally the diagnosis can be made presumptively on the basis of "Linguatula nodules" presented by acellular, partly hyalinized fibrous tissue surrounding a central mass of amorphous or calcified material in which structures of pentastomes are no longer found and only small remnants of the parasite's cuticle may be left in the center $[5,12,13]$.

The visceral case presented here was diagnosed as due to a species of Linguatula for several reasons.

Firstly, our patient had never travelled abroad. This ruled out Armillifer armillatus and the related species, which are strictly African ones. Secondly, the definitive hosts for Armillifer species are snakes of the genera Python and Bitis and neither of these is represented in Bulgaria. Thirdly, and most importantly, the pentastomid discovered by us had conspicuous spinules. The spinules were sufficient to identify it as a thirdstage larva of $L$. serrata and to differentiate it from all other pentastomids (Figure 1). As was mentioned above, our patient had never travelled abroad, so clearly the infection was contracted locally. Ours is the first report of human linguatuliasis in Bulgaria. Infestation by the larva of the tropical linguatulid Armillifer armillatus has occasionally been so severe in humans as to cause illness and even death (Cannon, 1942) [15]. In contrast with this, there has been, up to now, nothing to suggest that infestation by larvae of $L$. serrata is of any clinical importance [5]. Once the diagnosis has been made, treatment is not usually necessary in asymptomatic infection since the parasites degenerate after approximately two years $[6,12]$. Appropriate surgical intervention should be undertaken when intestinal obstruction or perforation develops. Free or encysted parasites in the eye should be removed surgically. Preventive measures include washing hands 
carefully before eating, not consuming raw or undercooked meat, not feeding dogs with raw

\section{References}

1. Dakubo JCB, Etwire VK, Kumoji R, Naaeder B. Human pentastomiasis: Acase report. WAJM. 2006;25(2):166-8.

2. Gutierrez Y. Diagnostic pathology of parasitic infections with clinical correlations. Philadelphia, London: Lea and Febiger; 1990. p. 483-6.

3. Lang Y, Garzozi H, Epstein Z, Barkay S, Gold D, Lengy J. Intraocular pentastomiasis causing unilateral glaucoma. $\mathrm{Br} \mathrm{J}$ Ophthalmol. 1987;71(5):391-5.

4. Maleky F. A case report of Linguatula serrata in human throat from Tehran central Iran. Indian J Med Sci. 2001;55(8):439-41.

5. Symmers WSC, Valteris K. Two cases of human infestation by larvae of Linguatula serrata. J Clin Path. 1950;3(3):212-9.

6. Lazo RF, Hidalgo E, Lazo JE, Bermeo A, Llaguno $\mathrm{M}$, Murillo $\mathrm{J}$, et al. Ocular linguatuliasis in Ecuador: case report and morphometric study of the larva of Linguatula serrata. Am J Trop Med Hyg. 1999;6093):405-9.

7. Sonobe K. Über Linguatuliden-Larven-Knotchen (sog. Pentastomen-Knotchen) der Leber des Menschen. Virchows Arch Path Anat. $1927 ; 263: 753-8$ meat of herbivores, avoiding contact with canine saliva and drinking water used by dogs or wild canids $[11,12,13]$.

8. Ivanov A, Kirkova Z, Iliev P, Uzunova K. A Case of Pentastomum denticulatum Infection in Goats. J Fac Vet Med Istanbul Univ. 2012;38(2):191-5.

9. Sambon LW. A synopsis of the family Linguatulidae. J Trop Med Hyg.1922;25:188-206; 391-428.

10. Yilmaz H, Cengiz ZT, Cicek M, Dulger AC. A nasopharyngeal human infestation caused by Linguatula serrata nymphs in Van province: a case report. Turkiye Parazitol Derg. 2011;35(1):47-9.

11. Baird JK, Kassebaum LJ, Ludwig GK. Hepatic granuloma in a man from North America caused by a nymph of Linguatula serrata. Pathology. 1988;20(2):198-9.

12. Tappe D, Buttner DW. Diagnosis of human visceral pentastomiasis. PLoS Negl Trop Dis. 2009;3:e320.

13. Tappe D, Winzer R, Büttner DW, Ströbel P, Stich A, Klinker H, et al. . Linguatuliasis in Germany. Emerg Infect Dis. 2006;12(6):1034-6.

14. Saupe E. Verkalke parasiten (Pentastomum denticulatum) in der Milz. Röntgenpraxis.1930;2: 401-5.

15. Cannon DA. Linguatulid infestation of man. Ann Trop Med Parasitol.1942;36:160-7. 